\title{
Development of strategic guidelines for agile Parts Ma- turity Management of engine subsystems in the automotive industry during series ramp-up
}

\author{
Simon Rapp ${ }^{1}$, Jonas Heimicke ${ }^{1}$, Jonas Weber ${ }^{1}$, Albert Albers ${ }^{1}$ \\ ${ }^{1}$ IPEK - Institute of Product Engineering, Karlsruhe Institute of Technology (KIT) \\ \{Simon.Rapp, Jonas.Heimicke, Jonas.Weber, Albert.Albers\}@kit.edu
}

\begin{abstract}
Background: The increasing innovation pressure on German car manufacturers leads to a significantly higher model and variant diversity whereas model cycles and development times decrease. Subsequently, the number of successive series ramp-ups also increases, which bears technical and economic challenges for the car manufacturers. Meanwhile, the car manufacturers face late or frequent variations of products and production processes during series ramp-up, which jeopardize the scheduling targets and a timely market launch and causes millions of dollars in losses. Aims: The aim of this contribution is to determine potential risk factors, which jeopardise the technical and economic success of a series ramp-up from the perspective of Parts Maturity Management. Regarding this, another aim is to determine potential negative causeeffect-relations between the identified risk factors and maturity level violations. This knowledge shall be used to develop strategic guidelines in order to anticipate or to manage their negative effects in a more effective way. Method: Surveys, interviews, document analysis and observations serve the identification of main causes of critical parts in the real-world context of a German car manufacturer. The knowledge gained is the basis for the development of strategic and agile-structuring guidelines. Results: The data analysis implies the existence of parts (e.g. exhaust turbocharger or crankcase), which are critical in every product generation and regularly jeopardise the project success. Concerning this matter, it has been possible to identify and illustrate five main risk factors and the associated cause-effect-relations. Especially, late or frequent engineering changes lead to maturity level violations during series ramp-up. These changes do not only influence the product development process but also tool manufacturingand supplier contracting-processes. For this matter, five strategic guidelines on how to deal with late or frequent engineering changes have been developed. Conclusions: Under the challenge of intensive engineering change management, this contribution was able to show a first indication of how, even in this highly regulated environment, the systematic use of product knowledge can be applied to increase the responsiveness of developers in a structured form. The underlying patterns can be transferred to other application areas.
\end{abstract}

Keywords: ASD - Agile Systems Design, Automotive Development, PGE - Product Generation Engineering, Engineering Change 


\section{Introduction}

On the one hand, the globally effective mega trends sustainability, urbanisation, individualisation and digitalisation put the automotive industry in a tight spot but on the other hand, they also enable technological and social innovations which lead to entirely new mobility concepts (Berret et al., 2017; Mogge, Schlick, Daniel, Fritz, \& Söndermann, 2019). The resulting innovation pressure leads to a significantly higher model and variant diversity whereas model cycles and development times decrease (Cornet, 2002). Subsequently, the number of successive series ramp-ups also increase, which bears technical and economic challenges for the car manufacturers (Nagel, 2011; Schuh, Kampker, \& Franzkoch, 2005; Wiesinger \& Housein, 2002). Meanwhile, the car manufacturers (OEM) face late or frequent variations of products and production processes during series ramp-up, which jeopardise scheduling targets and a timely market launch (Schuh et al., 2005; Wiesinger \& Housein, 2002).

This paper examines in-depth the challenges of Parts Maturity Management, which may jeopardise the technical and economic success of ramp-up in the automotive industry. In cooperation with a German OEM, the practical Parts Maturity Management processes during the rampup of an engine have been analysed to gain a deepening understanding of the cause-effectrelations of critical parts. As a result, five guidelines have been developed based on the knowledge gained and on principals for agile mechatronic system development. The purposeful implementation of agile-structuring elements to the Parts Maturity Management processes is paramount in order to increase the process stability against late or frequent engineering changes.

\section{State of the Art}

\subsection{Parts Maturity Management during series ramp-up}

An integrated management of production ramp-ups is necessary regarding the increasing number of series ramp-ups in less time caused by the increasing model and variant variety. Even a small postponement of the market launch determines success or failure of a car project (Dombrowski, Wullbrandt, \& Krenkel, 2018; Wiesinger \& Housein, 2002). Thereby, the Ramp-up Management becomes the economic success factor for an OEM concerning Time-to-Market and Time-to-Volume as well as the controlling of costs, quality and product complexity (Schmitt, Schuh, Gartzen, \& Schmitt, 2010).

The Ramp-up Management includes all measures for planning, steering and executing a production ramp-up. The production ramp-up describes the time window from the release of pilot production until reaching the production peak, the maximum planned production quantity per time unit. In order to be able to measure and steer the project progress as well as the maturity levels of products and production processes, synchronization points are planned within the project schedule. This approach allows to steer the product quality already from the concept phase and along the entire product development process (Schmitt \& Pfeifer, 2015; Schuh, Stölzle, \& Straube, 2008).

Concerning this matter, the Quality Management defines measurable requirements and targets for the product and its development process. Quality Gates (QG), Milestones and Maturity Levels are a form of above-named synchronisation points. Thereby, QGs divide the product development process into separate phases (Pfeifer, 2014). When a QG is reached, the results of the subordinate Milestones are evaluated in an aggregated approach and are the basis for planning the further project course. In this manner, the current degree of fulfilment of the project targets is confirmed or adjusted. However, a QG prohibits its pass-through until all criteria are fulfilled, and the next phase can be initiated (Pfeifer, 2014; Schmitt \& Pfeifer, 2015). Milestones are subordinately to QGs and separate these in smaller work packages. They enable a retrospective 
validation of work results, which are expected to a defined point in the project schedule. The aim is to define countermeasures to ensure the project success. Maturity Levels extend the concept of milestone validation. Maturity Levels capture the project progress as a basis for further escalations within the management hierarchy of a company. For this purpose, evaluation criteria are defined to evaluate the project risks in order to develop appropriate countermeasures. Based on this logic, a Maturity Management-model has been developed in the automotive industry (German Association of the Automotive Industry (VDA), 2009). This model covers the whole product development process until Start of Production (SOP) (Schmitt \& Pfeifer, 2015).

\begin{tabular}{|c|c|c|c|c|c|c|c|}
\hline \multicolumn{2}{|c|}{ Planning } & $\begin{array}{l}\text { duct-design } \\
\text { and } \\
\text { velopment }\end{array}$ & \multicolumn{2}{|c|}{$\begin{array}{l}\text { Process-design } \\
\text { and } \\
\text {-development }\end{array}$} & $\begin{array}{l}\text { Product- and } \\
\text { process-validation }\end{array}$ & \multicolumn{2}{|c|}{$\begin{array}{l}\text { Review, evaluation } \\
\text { and corrective } \\
\text { measures }\end{array}$} \\
\hline \multicolumn{6}{|c|}{ Concept phase } & \multicolumn{2}{|c|}{ Series production } \\
\hline $\begin{array}{l}\text { Innovation } \\
\text { release }\end{array}$ & $\begin{array}{l}\text { Re- } \\
\text { quirements } \\
\text { Procurement } \\
\text { scope }\end{array}$ & $\begin{array}{l}\text { Definition } \\
\text { Supply } \\
\text { Chain }\end{array}$ & $\begin{array}{l}\text { Specifi- } \\
\text { cation } \\
\text { release }\end{array}$ & $\begin{array}{c}\text { Produc } \\
\text { Planni }\end{array}$ & $\begin{array}{l}\text { Series } \\
\text { tooling }\end{array}$ & $\begin{array}{l}\text { duct- } \\
\text { nd } \\
\text { eess- } \\
\text { ease }\end{array}$ & $\begin{array}{c}\text { Project } \\
\text { completion }\end{array}$ \\
\hline
\end{tabular}

Figure 1. Maturity levels defined by the Maturity Management-model of the automotive industry (German Association of the Automotive Industry (VDA), 2009)

Especially, the monitoring and steering of the product maturity level is essential to the overall project success. A product maturity level is defined as the "... degree of fulfilment of the customer's requirements (customer view) taking into account additional information that results from the solution approach (engineering view)” (Krehmer \& Paetzold, 2008). Thereby, holistic Maturity Management-models, which go beyond a sole parts management, become essential due to an increasing product and parts complexity as well as an increasing number of external development partners (Krehmer \& Paetzold, 2008). Such models steer the maturity level by considering the three dimensions Product, Process and Human (Müller, Bär, \& Weber, 2005). A well-established method to steer the product's maturity in the automotive industry is e.g. the Advanced Product Quality Planning (APQP) process. APQP is described as a “... structured method for defining and executing the actions necessary to ensure that a product satisfies the customer" (Stamatis, 2018, p. xxiii). As a guideline along the development process, it integrates well-known quality management methodologies like e.g. the Failure Mode and Effects Analysis (FMEA) from AIAG (2008) and the Production Part Approval Process (PPAP).

\subsection{Development of agile processes according to ASD - Agile Systems Design and by applying reference system-based knowledge}

The Maturity Management approach is just one of many to manage complexity during product development (Schmitt \& Pfeifer, 2015). Ropohl and Aggteleky (1975) describe product development processes as "[...] the (continuous) transformation of a (initial vague) system of objectives into a specific system of objects through an operation system” (Albers, Braun, \& Muschik, 2010), which can be defined as a problem-solving process. Thus, all activities of product development can be interpreted as problem-solving processes as well. SPALTEN is a German acronym for the seven phases Situation analysis, Problem Containment, Alternative Solutions, Selection of Solutions, Consequences Analysis, Make Decision and Recapitulate \& Learn. It is a universal approach to structure and implement problem solving processes and is not limited to special problems or situations. (Albers, Reiß, et al. 2016)

For supporting product development processes ASD - Agile Systems Design defines an ,[...] integrated, structured approach for the agile development of mechatronic systems, the associated product strategy as well as the validation and production systems [...]“ (Albers et al., 2018). 
The approach bases on nine principles, which support the user during the company- and context-specific design and application of agile-structuring practices and during the determination of an appropriate level of agility within the product development process (Albers, Heimicke et al., 2019). ASD derives from the knowledge that complex, complicated, simple and chaotic problems constantly coexist in a development process. Thus, neither solely structured nor solely agile project structures are purposeful (Boehm \& Turner, 2003; Snowden \& Boone, 2007). In conclusion, the appropriate level of agility must be defined according to the current situation and conditions (Heimicke, Freire, Breitschuh, \& Albers, 2019).

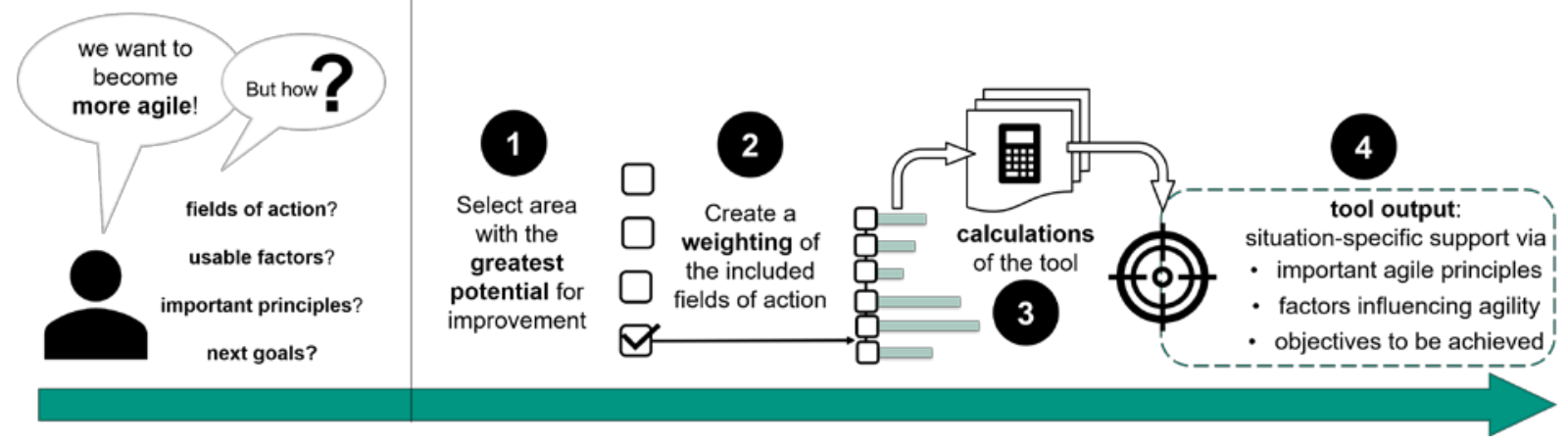

Figure 2. Methodological support for the alignment of agile transition (Albers et al., 2020)

In this context, Albers et al. (2020) have developed a methodology, which supports understanding of the situation regarding agile capabilities as well as for the identification of relevant agile factors and ASD-principles. These factors and principles are used to develop a system of objectives, which serves as a profile for a situation-specific agile-structuring process solution. The methodology supports process authors specifically in the following steps (Albers et al., 2020):

- Identification of actual situation of a company or organizational unit regarding agility

- Identification of appropriate fields of action for the change to agile

- Proposal of appropriate factors for the specification of the system of objectives

- Prioritization of the nine principles of ASD for the specific case of the user

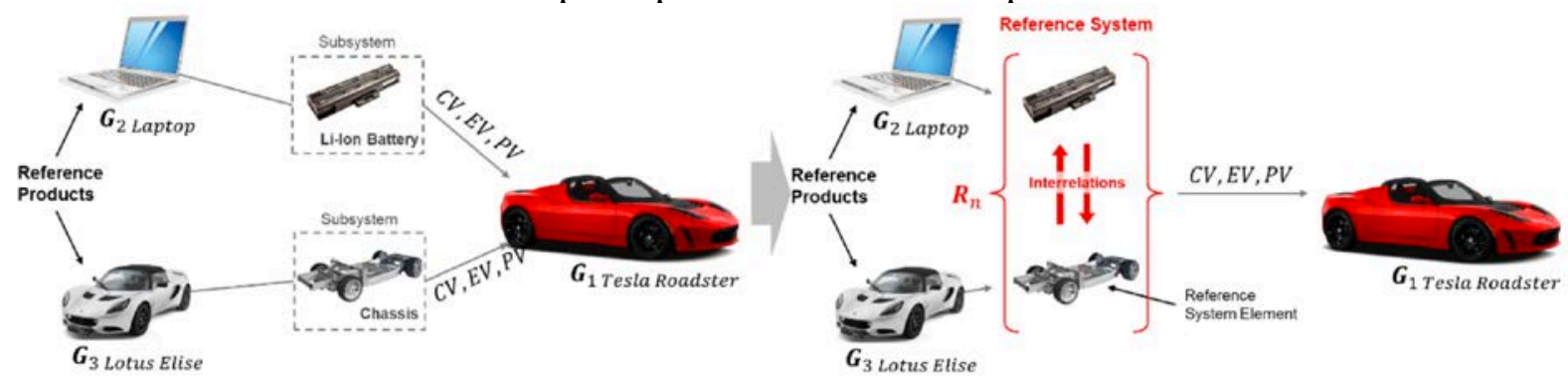

Figure 3. PGE model without and with reference system - example: Tesla Roadster (Albers et al., 2019)

The ASD approach is largely based on the mindsets, methods and processes of PGE - Product Generation Engineering (Albers et al., 2018). According to the description model, the development of technical products includes both a carryover variation and a new development of subsystems (Albers, Bursac, \& Wintergerst, 2015). Regarding this, the basis for a new product generation is always the reference system which consists of subsystems e.g. from previous product generations or competitor products (Albers, Rapp et al., 2019).

These references are transferred to the succeeding product generation by three types of variation: carryover variation (CV), embodiment variation (EV) and principle variation (PV), whereas PV and EV together form the new development share. Accordingly, an engineering change can be a PV, as well as an EV or CV depending on its type and extent. In order to take this central aspect of PGE fully into account, the term engineering change is replaced by engineering variation. The PGE models ultimately serves (among other things) the development of 
new methods and processes that support the planning and control of product development (Albers et al., 2015; Albers, Bursac, \& Rapp, 2016).

\section{Need for Research and Research Approach}

Westkämper (2003), Lanza and Fleischer (2005), Schuh, Kampker, and Franzkoch (2005), Schmitt, Schuh, Gartzen, and Schmitt (2010) and Szabó (2018) emphasize the importance of a successful Ramp-up Management to an OEM's economic success. An efficient ramp-up can yield up to additional 5\%-points of the model rate of return over its total lifetime (Schuh et al., 2005). In contrast, a six-month postponement of the market launch may lead to a possible loss of 6.465 billion USD considering an annual production volume of 500,000 units over a total production period of seven years (Szabó, 2018). However, 47\% of the production ramp-ups in the automotive industry are neither technically nor economically successful (Schuh et al., 2005). This situation is aggravated by the fact that the production ramp-up has not been researched in-depth in the past (Schuh et al., 2005). Accordingly, the research need emerges, to analyse the ramp-up and its Maturity Management. Thereby, the overall aim is to increase the process stability and response capacity of the Maturity Management to unpredicted challenges. First, it is necessary to identify the challenges and risk factors that may jeopardise the ramp-up success from the perspective of the Parts Maturity Management. Therefore, it is also necessary to illustrate the relations between these risk factors and the maturity level. For this purpose, the exhaust turbocharger and the crankcase of an engine serve as references to identify potential risk factors for a critical maturity level before SOP. The knowledge gained can be used to proactively steer the parts' maturity level in succeeding product generations. The research questions, which shall result in a better understanding of the problem, are defined as:

- Which challenges exist during ramp-up in the automotive development from the perspective of Parts Maturity Management?

- Which factors jeopardise the success of ramp-up from the perspective of Parts Maturity Management?

- To what extent appear these factors recurrent in Parts Maturity Management?

Based on the greater awareness of the situation and the developed understanding of critical cause-effect-relations, alternative guidelines can be developed to better manage these critical cause-effect-relations during ramp-up. The primary goal of the guidelines is the integration of ASD in order to include agile-structuring process solutions to the Parts Maturity Management. Therefore, the following research question has been derived:

- How can strategic guidelines be defined in order to improve the overall management of the identified critical cause-effect-relations by implementing agile-structuring process solutions to the Parts Maturity Management?

The research questions have been studied on within a case study in cooperation with a German OEM. The case study has been conducted according to the guidelines of Yin (2014). The last research question has been answered based on the identified critical cause-effect-relations. During the six-month cooperation, deeper insights into the Maturity Management practices of an engine project have been gained. The OEM manages the three maturity levels first off-tool parts, off-tool parts and sampling during series ramp-up. With first off-tool parts, optimisation potentials for the series production tools, machine and equipment parameters as well as production processes are identified. Off-tool parts are used to validate requirement specifications. The Parts Maturity Management prioritises a part as critical, if the part is not available with the required maturity level at start of assembly. Interviews, surveys and observations served to answer the research questions one to three. In the following, fields of action could be identified based on the data analysis. The acquired expert knowledge as well as the methodology, developed by Albers et al. (2020), have been used to define the guidelines. 


\section{Results}

\subsection{Challenges and risk factors of Parts Maturity Management}

25 employees participated in a survey to the five most common causes for maturity level violations. Among the persons interviewed are representatives of the strategic project lead, Quality Management, Logistics, Procurement, Supplier Quality Management and Research \& Development. The specified answer options were determined from a previous document analysis. Here, 36 report sheets were analysed. In the event of maturity level violations, these standardized report sheets must be created by the part-responsible developer. In this way, the developer justifies the maturity level violations. During the document analysis, the technical justifications in these report sheets were sorted by topic (see y-axis in Figure 4). In a second step, the number of mentions from interviewees and report sheets was counted and accumulated (x-axis). Finally, the various causes for critical parts could be condensed onto the following five main factors (A) late or frequent engineering variations during series ramp-up, (B) late or missing design releases, (C) Late or missing series production tool order or variations, (D) late or missing supplier assignment, (E) missing date transparency. The results of the survey and the document analysis are shown in Figure 4.

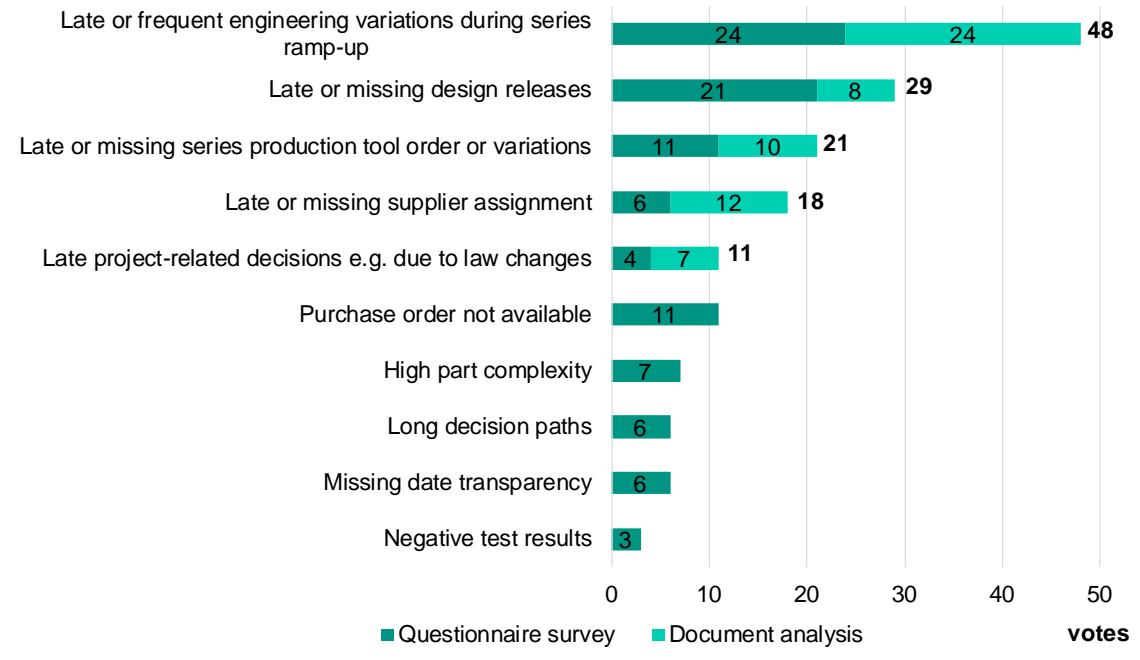

Figure 4. Overview over reasons for critical parts during ramp-up phase.

These factors do not occur independently but can also foster each other. As an example, engineering variations also influence the supplier assignment as well as the tool manufacturing process. As a result, parts cannot be delivered with the desired maturity level to production tests or series production on time. This jeopardises the technical and economic success of series rampup from the perspective of Parts Maturity Management. If there are no customer suitable parts available until SOP and, in the worst case, the SOP must be postponed, this can delay a timely market launch. As shown in section 2, this leads to further economic risks.

Through further discussions and interviews on these first results, it became clear that the risk factor late or frequent engineering variations during series ramp-up is one of the main causes of a maturity level violation. This is because engineering variations have extensive effects to all departments involved in series ramp-up. They do not only delay the development and construction process but also lead to late supplier contracts due to extended or renewed negotiations and delays the tool manufacturing process due to adjustments. This can also be illustrated using the example of the development of exhaust turbochargers and crankcases. The exhaust turbocharger is a subsystem that jeopardises the success of any engine project. The cause analysis has shown that this can be explained on the one hand by the complexity of the turbocharger and on the other hand by the long tool and part manufacturing times. These are usually six months 
for tool manufacturing and production of prototypes, nine months for small series tools and over one year for series tools. If late engineering variations, which also require tool adjustments, must be carried out in this process, milestones cannot be met on time due to long manufacturing times. At this point the question arises as to whether and how late engineering variations can be anticipated or avoided entirely. If late variations are unavoidable, it should also be clarified how these are dealt with and the associated effects during ramp-up.

\subsection{Development of strategic guidelines in the context of late or frequent engineering variations during series ramp-up}

The focus was placed on managing late or frequent variations during series ramp-up. Although these variations certainly only cover a part of numerous causes, the research has shown that from the perspective of Maturity Management these represent a central risk factor with a large lever due to their extensive effects. Through early anticipation of engineering variations based on product generation knowledge and through close monitoring, the project risk in form of late part availability with the required maturity level should be reduced. Based on an in-depth analysis with the developers of exhaust turbocharger and crankcase the existing knowledge about possible causes of late engineering variations were detailed.

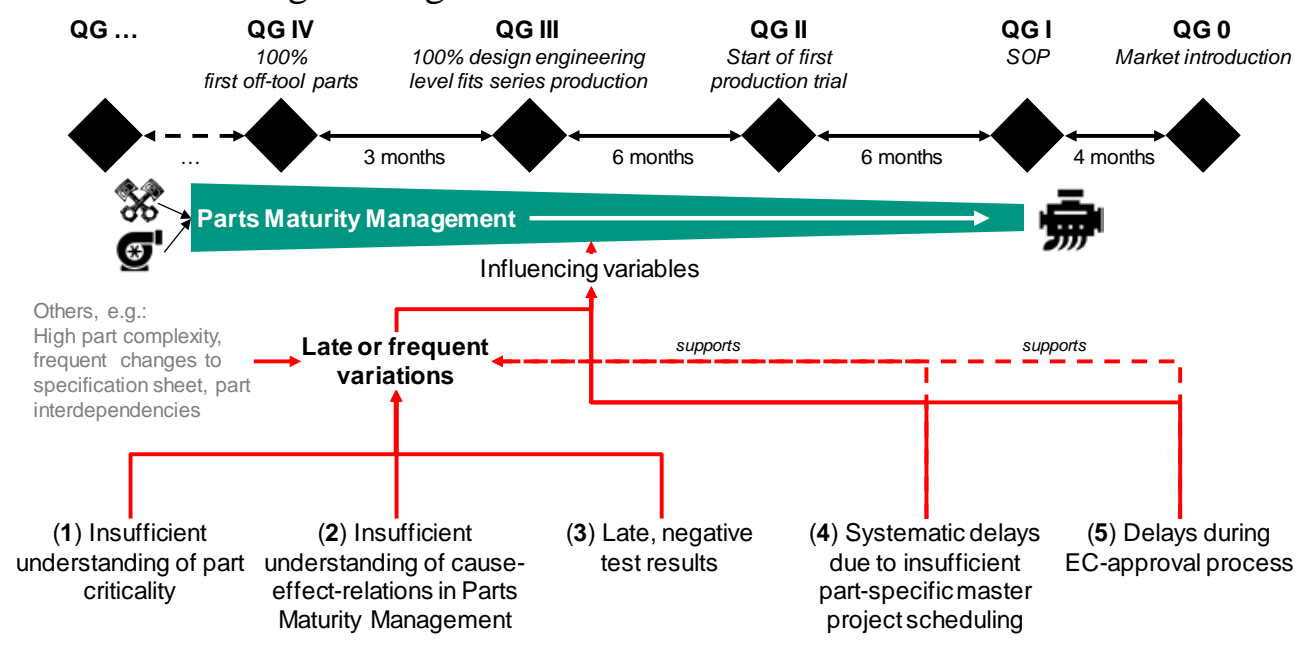

Figure 5. Identified causes for late or frequent variations during ramp-up and other influencing variables

These causes include, among others: (1) insufficient understanding of part criticality, (2) insufficient understanding of cause-effect-relations in Maturity Management, (3) late, negative test results, (4) systematic delays due to insufficient part-specific master project scheduling and (5) delays during EC-approval processes. While causes one to three are directly related to late or frequent variations, causes four and five foster late variations and can at the same time be viewed as basic risk factors for Maturity Management. In addition, other factors could be identified that foster late or frequent variations. However, these factors were not analysed further because the influence on these factors was assessed as low. Figure 5 illustrates the identified causes for late or frequent variations in the context of series ramp-up. The upper section depicts the QGs within the project master schedule of an engine project. Thereby, the Parts Maturity Management starts approximately six months before QG IV. The lower section depicts the identified causes. Based on the increased awareness of the situation and the problem, guidelines can be developed, considering the ASD approach and applying the methodology according to Albers et al. (2020). In consultation with a method expert, the relevant principles are then determined with the methodology. In addition, the desired effects on Maturity Management can be identified together. Therefore, the ASD principles recommend influencing variables that lead to the desired effects. In this regard, the methodology according to Albers et al. (2020) simplify 
the guideline development by suggesting principles and influencing factors that are specific to the situation and user needs. Finally, the situation and problem awareness, the identified ASD principles and the associated factors can be used to finalise the guidelines. In the following, the effort and benefits associated with the implementation of the guidelines are assessed.

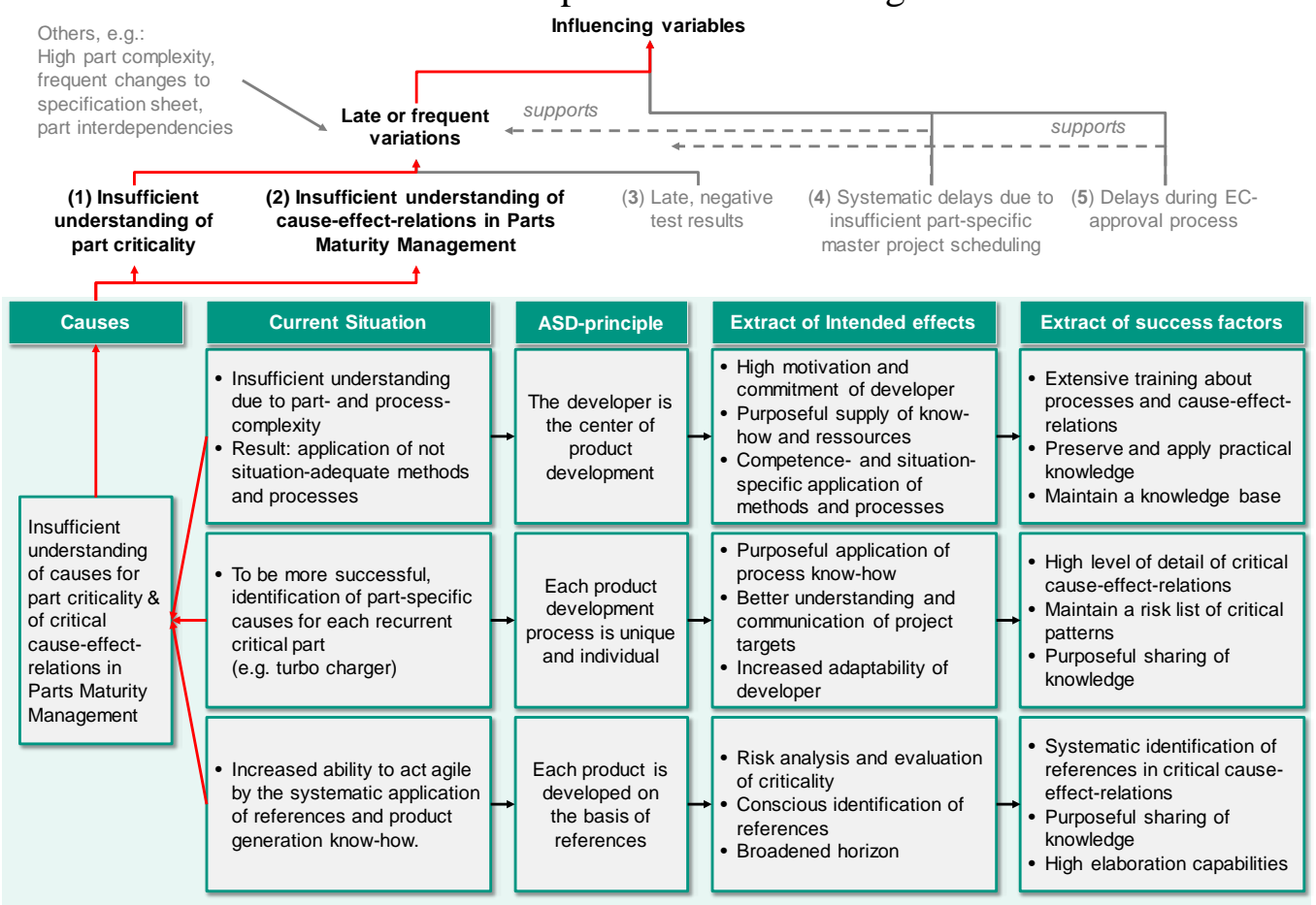

Figure 6. Overview over root-causes, assigned ASD-principles, intended effects and success factors to avoid late or frequent design variations and improve the Parts Maturity Management

For example, late negative test results are one of the main causes of late engineering variations. This mostly results from the complexity of the subsystem (e.g. exhaust turbocharger), which can currently only be captured to a limited extent with simulation models. In the future, these simulation models will be optimised in the course of digitisation, which will involve a great deal of work and time. Systematic missed deadlines of the project master plan result from the component-specific properties, which are usually only considered to a limited extent in the project master plan. The consideration of product generation knowledge in the project plans relates to a detailed analysis of the cause and a complex synchronisation with project plans of other subsystems and the overall project plans of engine and vehicle. On the other hand, the unplanned EC lead times can be reduced with less effort, which in this case is due to a lack of responsibility and drive by the applicant. Clarifying the causes of critical components and subsystems also means less effort. It is assumed that the identification of critical cause-effect-relations and the associated education can generate benefits for the Maturity Management. For this reason, the lack of understanding of the causes of critical subsystems and the causal relations are discussed in more detail below. In order to define a profile for the strategic guidelines, the actual causes of the lack of understanding are first identified (Figure 6.).

- First, the lack of transparency and possible ambiguities about the critical cause-effectrelations which arise from the large number of subsystems to be controlled, can hinder the identification of critical subsystems. In addition, a lack of understanding of the causes of critical subsystems can make it difficult to adequately use methods and processes and may lead to frequent engineering variations. In order to support the developer (e.g. external development partner) in his activities in the context of Maturity Management and to improve the maturity level, the knowledge and methods should be adapted to the knowledge and skills of the developer depending on the situation and his needs. 
This approach corresponds to the first ASD principle The developer is the centre of product development. The intended effects are a high level of motivation through a better situational awareness, the purposeful application of know-how and resources and the initiation of lifelong learning. Relevant factors in the implementation of this principle are, for example, the detailed education of the developer in the processes and interdependencies of Maturity Management, the preservation \& application of experience from other employees and the maintenance of a knowledge base.

- Secondly, general cause-effect-relations in Maturity Management were identified, but each recurring critical subsystem should be analysed individually in order to gain a better situational awareness. This approach corresponds to the ASD principle Each product development process is unique and individual. The intended effects are the purposeful and situation-specific application of process knowledge, a better understanding and communication of the component-specific project goals and an increased adaptability of the employees to new situations. Relevant factors are keeping a risk list to preserve critical cause-effect-relations and training employees on methodological competence.

- Thirdly, a lack of past project experience (product knowledge) can be the cause of less specific problem awareness. In this regard, the consideration and implementation of the ASD principle Each product is developed on the basis of references is purposeful. The intended effects are the deliberate identification of references within product groups and between generations. The references obtained in this way can then be used for a situation-specific risk analysis and criticality assessment of subsystems by the user. Relevant factors are distinct specialist competencies and expert knowledge of the developers, which ultimately also enable the systematic search for references in the causal relationships of the Maturity Management of other subsystems.

The knowledge gained about the root causes, which can lead to a lack of understanding, coupled with the knowledge and the implications of the ASD principles, together form the framework for the strategic guideline. It is divided into four steps (Figure 7.).

1. Identification of recurrent critical parts: First, the interdisciplinary work group for Maturity Management should identify all recurring critical components in a joint meeting (e.g. exhaust turbocharger). In this step, the application of experience and the purposeful use of process knowledge are of crucial importance.

2. Deep-Dive critical cause-effect-relations: Second, it is now necessary to investigate why these subsystems become critical repeatedly and which cause-effect-relations exist in their Maturity Management. In this regard, expert interviews should primarily be carried out with developers and the departments involved, as well as document analyses. The aim is to identify references in the cause-effect-relations of Maturity Management. This requires the experience of developers and those involved in Maturity Management. The newly gained knowledge can finally be summarized in a risk list.

3. Education and sensitisation: Thirdly, the prepared knowledge can be used for training purposes and for raising awareness. This can primarily affect (new) employees or external development partners who, for example, are not familiar with the processes and cause-effect-relations of Maturity Management. The main aim of this process step is to introduce employees to the processes and interdependencies of Maturity Management and thus to make employees more aware of it. This should enable, for example, a situation-specific risk analysis and criticality assessment of the effects of engineering variations on the maturity level by the developer according to the ASD principles.

4. Documentation and continuous improvement: Finally, the knowledge gained during the process and identified potential for improvement should be documented in digital form. In this way, it can be made available to others or reassessed at later times. At the same time, this requires continuous maintenance of the knowledge base. This allows 
expert knowledge of experienced employees to be preserved and made available to new employees. Ultimately, lifelong learning of employees is made possible.

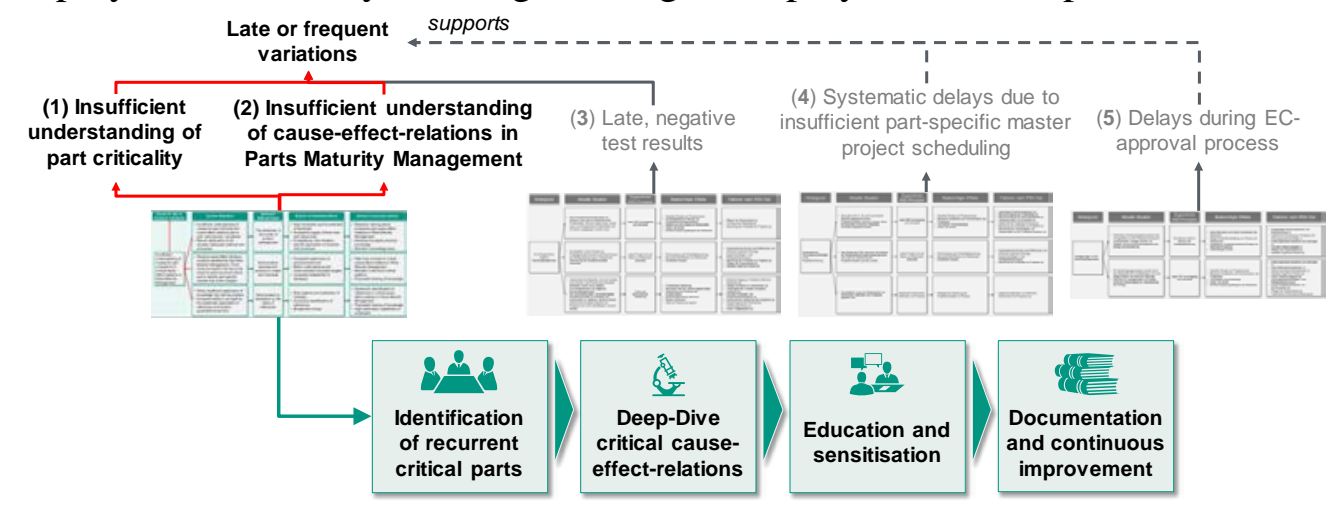

Figure 7. Definition of strategic guideline based on the framework depictured in Figure 6

\subsection{Evaluation of the developed strategic guidelines}

Risk factors and critical cause-effect-relations could be identified based on an in-depth situation analysis and problem containment. This acquired knowledge served using the methodology from Albers et al. (2020) for the development of a method profile and the following definition of strategic guidelines. The feasibility, effects and consequences were assessed based on an initial evaluation as part of further expert interviews. The goal-oriented identification of central risk factors of the Maturity Management during ramp-up and the development of strategic guidelines for an agile Parts Maturity Management can be assessed positively. There are three possible approaches for managing late engineering variations, thus covering a wide range of alternative recommendations. One approach is to avoid later, more frequent or unplanned variations by, for example, optimizing simulation models or better adapting project master plans to the duration of product and production trials. A second approach is to try to better anticipate engineering variations and their consequences as well as react more quickly to them. Clarifying the causes of critical subsystems and the cause-effect-relations in Maturity Management can help to timely initiate countermeasures. Ultimately, not all engineering variations can be avoided. Hence, the third approach addresses the better handling of the inevitable consequences. For example, raising awareness of the standard-compliant implementation of EC-processes in accordance with the standard duration can foster faster implementation of the variations and subsequent processes in the organization. The asked employees evaluate all guidelines as feasible and with process-improving effects on Parts Maturity Management. However, there is an additional effort in the form of time and work, which scales with the guideline's extend and is incurred in addition to the daily business. In this regard, the effort increases with the ability to avoid or anticipate engineering variations. However, cooperating departments must be convinced of the benefits of Maturity Management and the developed guidelines.

\section{Discussion and Conclusion}

From the point of view of Maturity Management, the results illustrate and emphasize the variety of critical risk factors during series ramp-up. It becomes clear that especially late or frequent engineering variations during series ramp-up represent an essential risk factor for the economic and technical success of ramp-up. In the context of this study, this fact results from the finding that complicated and complex cause-effect-relations coexist in Maturity Management and the consequences of an engineering variation cannot be analysed in isolation. Three possible approaches are recommended for managing variations and their consequences to Maturity Management. First, an attempt should be made to avoid late variations in order to keep the project 
risk as low as possible. Since this will certainly not always be possible in practice, attempts can also be made to anticipate late engineering variations and their consequences, to timely initiate countermeasures and to communicate the current status within the organization. After all, not all variations can be avoided or anticipated. At this point, it is important to develop methods that enable the organization to act in agile manners and minimize the negative consequences of variations. Therefore, a method profile for agile-structuring process solutions has been developed based on an in-depth situation analysis and by the application of the methodology from Albers et al. (2020). The description model of PGE is of central importance in the identification and description of critical patterns and interdependencies in Maturity Management. This knowledge should be used as reference in succeeding product generations in order to identify critical patterns at an early project stage and to implement purposeful process adjustments. In this way, the degree of flexibility in the otherwise clearly structured Maturity Management processes can be adapted to the current situation. As part of the case study, it was shown which causes can lead to maturity level violations and which interdependencies exist. In a next step, the developed methodological support must be applied and tested in practice. Finally, the current results should be enhanced by studies of Maturity Management processes at other OEMs.

\section{References}

AIAG (2008). Potential Failure Mode and Effect Analysis (FMEA), 4th Edition. Automotive Industry Action Group. ISBN 978-1-60534-136-1.Albers, A. (2010). The integrated product engineering model (iPeM) and its central hypotheses. Proceedings of the TMCE, 12-16.

Albers, A., Braun, A., \& Muschik, S. (2010). Ein Beitrag zum Verständnis des Aktivitätsbegriffs im System der Produktentstehung. In M. S. Maurer (Ed.), Tag des Systems-Engineering, TdSE2010; (pp. 87-96). München: Hanser.

Albers, A., Bursac, N., \& Rapp, S. (2016). PGE - Produktgenerationsentwicklung am Beispiel des Zweimassenschwungrads: Springer-Verlag Berlin Heidelberg.

Albers, A., Bursac, N., \& Wintergerst, E. (2015). Produktgenerationsentwicklung: Bedeutung und Herausforderungen aus einer entwicklungsmethodischen Perspektive. Karlsruhe.

Albers, A., Heimicke, J., Trost, S., \& Spadinger, M. (2020). Alignment of the change to agile through method-supported evaluation of agile principles in physical product development. Procedia CIRP, in press.

Albers, A., Heimicke, J., Spadinger, M., Reiss, N., Breitschuh, J., Richter, T., . . Marthaler, F. (2019). A systematic approach to situation-adequate mechatronic system development by ASD - Agile Systems Design. Procedia CIRP, 84, 1015-1022. https://doi.org/10.1016/j.procir.2019.03.312

Albers, A., Heimicke, J., Walter, B., Basedow, G. N., Reiß, N., Heitger, N., . . B Bursac, N. (2018). Product Profiles: Modelling customer benefits as a foundation to bring inventions to innovations. Procedia CIRP, 70, 253-258. https://doi.org/10.1016/j.procir.2018.02.044

Albers, A., Rapp, S., Spadinger, M., Richter, T., Birk, C., Marthaler, F., ... Wessels, H. (2019). The Reference System in the Model of PGE: Proposing a Generalized Description of Reference Products and their Interrelations. Proceedings of the Design Society: International Conference on Engineering Design, 1(1), 1693-1702. https://doi.org/10.1017/dsi.2019.175

Albers, A., Reiß, N., Bursac, N., \& Breitschuh, J. (2016). 15 Years of Spalten Problem Solving in Methodology in Product Development. Trondheim, Norway.

Berret, M., Bernhart, W., Winterhoff, M., Seyger, R., Kirstetter, E., \& Riederle, S. (April 2017). Automotive Disruption Radar: Issue \#1. Tracking disruption signals in the automotive industry. München. 
Boehm, B., \& Turner, R. (2003). Using risk to balance agile and plan- driven methods. Computer, 36(6), 57-66. https://doi.org/10.1109/MC.2003.1204376

Bormann, R., Fink, P., \& Holzapfel, H. (2018). Die Zukunft der deutschen Automobilindustrie: Transformation by Disaster oder by Design? WISO-Diskurs: 03/2018. Bonn: FriedrichEbert-Stiftung, Abteilung Wirtschafts- und Sozialpolitik.

Cornet, A. (2002). Plattformkonzepte in der Automobilentwicklung (Gabler edition Wissenschaft). Wiesbaden: Deutscher Universitätsverlag; Imprint.

Dombrowski, U., Wullbrandt, J., \& Krenkel, P. (2018). Industrie 4.0 in production ramp-up management. Procedia Manufacturing, 17, 1015-1022.

German Association of the Automotive Industry (VDA) (10/2009). Produktentstehung: Reifegradabsicherung für Neuteile: Methoden, Messgrößen, Dokumentationen, Checklisten; VDA/QMC-Projektdokumentation.

Heimicke, J., Freire, G., Breitschuh, J. \& Albers, A. (2019). Determining degrees of complexity of different development situations within business processes in engineering sector. 41st R\&D Management Conference 2019

Krehmer, H., \& Paetzold, K. (2008). Eine Betrachtung zur ganzheitlichen Abschätzung des Produktreifegrades auf Basis des Verhaltens. Design for X, 19, 67-78.

Lanza, G., \& Fleischer, J. (2005). OEE-Prognose im Produktionsanlauf: Simulationsbasierte Anlaufunterstützung mittels Kennzahlen. Werkstatttechnik Online, 95(7/8), 554-558.

Mogge, F., Schlick, T., Daniel, F., Fritz, K. O., \& Söndermann, C. (2019). In the heat of the mobility revolution: How automotive suppliers can master the industry's transformation. München.

Müller, M., Bär, T., \& Weber, C. (2005). Was ist Reifegrad? Design for X, 16, 17-26.

Nagel, J. (2011). Risikoorientiertes Anlaufmanagement. Zugl.: Cottbus, Techn. Univ., Diss., 2010 (1. Aufl.). Gabler research. Wiesbaden: Gabler.

Pfeifer, T. (Ed.) (2014). Masing Handbuch Qualitätsmanagement (6., überarb. Aufl.). München, Wien: Hanser.

Ropohl, G., \& Aggteleky, B. (1975). Systemtechnik: Grundlagen und Anwendung. München, Wien: Hanser.

Schmitt, R., \& Pfeifer, T. (2015). Qualitätsmanagement: Strategien - Methoden - Techniken (5., überarb. Aufl.). München [u.a.]: Hanser.

Schmitt, R., Schuh, G., Gartzen, T., \& Schmitt, S. (2010). Das Aachener Modell zum interdisziplinären Anlaufmanagement: Entwicklung von Entscheidungsmodellen im Produktionsanlauf (wt Werkstattstechnik online No. 4).

Schuh, G., Kampker, A., \& Franzkoch, B. (May 2005). Anlaufmanagement: Kosten senken Anlaufzeit verkürzen - Qualität sichern (wt Werkstattstechnik online No. 5).

Schuh, G., Stölzle, W., \& Straube, F. (Eds.) (2008). VDI-[Buch]. Anlaufmanagement in der Automobilindustrie erfolgreich umsetzen: Ein Leitfaden für die Praxis. Berlin, Heidelberg: Springer.

Snowden, D.J., \& Boone, M.E. (2007). A Leader's Framework for Decision Making. Harvard Business Review, 85(11), 68-77.

Stamatis, D. H. (2018). Advanced Product Quality Planning: The Road to Success. CRC Press.

Szabó, K. (2018). Ramp-up Process Improvement Practices for Time-to-Market Reduction. Periodica Polytechnica Social and Management Sciences, 26(1), 19-29.

Westkämper, E. (2003). Assembly and Disassembly Processes in Product Life Cycle Perspectives. CIRP Annals - Manufacturing Technology, 52(2), 579-588.

Wiesinger, G., \& Housein, G. (2002). Schneller Produktionsanlauf von Serienprodukten: Wettbewerbsvorteile durch ein anforderungsgerechtes Anlaufmanagement.

Yin, R. K. (2014). Case study research: Design and methods (5. ed.). 